\title{
A Study of Solvent Effects in the Solvolysis of Propargyl Chloroformate
}

\author{
Malcolm J. D’Souza, ${ }^{1}$ Anthony M. Darrington, ${ }^{1}$ and Dennis N. Kevill ${ }^{2}$ \\ ${ }^{1}$ Department of Chemistry, Wesley College, 120 North State Street, Dover, DE 19901-3875, USA \\ ${ }^{2}$ Department of Chemistry and Biochemistry, Northern Illinois University, DeKalb, IL 60115-2862, USA
}

Correspondence should be addressed to Malcolm J. D’Souza, dsouzama@wesley.edu and Dennis N. Kevill, dkevill@niu.edu

Received 24 January 2011; Accepted 8 March 2011

Academic Editor: V. P. Kukhar

Copyright (c) 2011 Malcolm J. D'Souza et al. This is an open access article distributed under the Creative Commons Attribution License, which permits unrestricted use, distribution, and reproduction in any medium, provided the original work is properly cited.

\begin{abstract}
The specific rates of solvolysis of propargyl chloroformate (1) are analyzed in 22 solvents of widely varying nucleophilicity and ionizing power values at $25.0^{\circ} \mathrm{C}$ using the extended Grunwald-Winstein equation. Sensitivities to solvent nucleophilicity $(l)$ of 1.37 and to solvent ionizing power $(\mathrm{m})$ of 0.47 suggest a bimolecular process with the formation of a tetrahedral intermediate. A plot of the rates of solvolysis of $\mathbf{1}$ against those previously reported for phenyl chloroformate (2) results in a correlation coefficient $(R)$ of 0.996 , a slope of 0.86 , and an $F$-test value of 2161 . The unequivocal correlation between these two substrates attests that the stepwise association-dissociation $\left(\mathrm{A}_{\mathrm{N}}+\mathrm{D}_{\mathrm{N}}\right)$ mechanism previously proposed for $\mathbf{2}$ is also operative in $\mathbf{1}$.
\end{abstract}

\section{Introduction}

Propargyl chloroformate (1) has been shown to be a very useful reagent that is used to introduce the propargyloxycarbonyl protecting group in reaction selective chemistry [1-3]. It has also found use in polymerizable acrylic compositions for the paint industry [4], and like other chloroformate esters, it could pose an environmental hazard [5] as chloroformate esters that readily react with moisture and have a corrosive effect on the human respiratory system [6].

In Figure 1, the molecular structures and 3D structures of propargyl $\left(1,1^{\prime}\right)$ and phenyl $\left(2,2^{\prime}\right)$ chloroformate are shown in their most stable configuration $[7,8]$ where the $\mathrm{C}=\mathrm{O}$ is syn with respect to the alkynyl or aryl moiety, that is, the halogen atom is in a trans position with respect to the alkynyl or aryl group.

In physical organic chemistry, linear free energy relationships (LFERs) such as the simple (1) [9] and extended (2) [10] Grunwald-Winstein equations are utilized to evaluate solvolytic mechanisms of a variety of substrates. In (1) and (2), $k$ and $k_{o}$ are the specific rates of solvolysis of a substrate in a given solvent and in the standard solvent ( $80 \%$ ethanol), respectively, $m$ represents the sensitivity to changes in the solvent ionizing power $Y_{\mathrm{X}}$ (based on the solvolysis of 1- or 2adamantyl derivatives) [11-15], $l$ is the sensitivity to changes in solvent nucleophilicity $N_{\mathrm{T}}$ (based on the solvolysis of $S$ methyldibenzothiophenium ion) $[16,17]$, and $c$ is a constant (residual) term

$$
\begin{gathered}
\log \left(\frac{k}{k_{o}}\right)=m Y_{\mathrm{X}}+c, \\
\log \left(\frac{k}{k_{o}}\right)=l N_{\mathrm{T}}+m Y_{\mathrm{X}}+c .
\end{gathered}
$$

Equations (1) and (2) have been successfully used to correlate unimolecular ionization $\left(\mathrm{S}_{\mathrm{N}} 1+\mathrm{E} 1\right)$ and bimolecular nucleophilically solvent-assisted $\left(\mathrm{S}_{\mathrm{N}} 2\right.$ and/or E2) reactions [18-22]. For compounds where resonance delocalization was possible between the reaction site and an adjacent $\pi$-system or for solvolyses of $\alpha$-haloalkyl aryl compounds that proceed via anchimeric assistance $\left(k_{\Delta}\right)$, we proposed $[22,23]$ adding an additional term, the aromatic ring parameter $I$, to (1) 

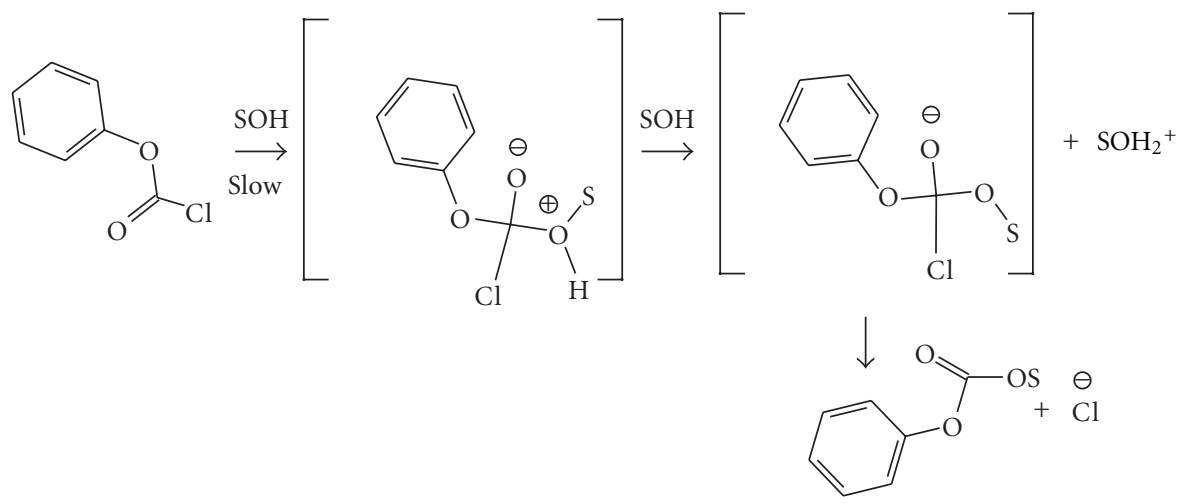

Scheme 1: Stepwise addition-elimination mechanism through a tetrahedral intermediate for phenyl chloroformate (3).

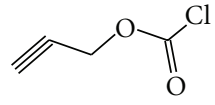

1

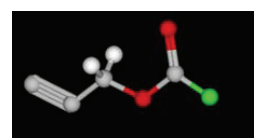

$\mathbf{1}^{\prime}$<smiles>O=C(Cl)Oc1ccccc1</smiles>

2

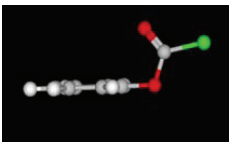

$2^{\prime}$

FIGURE 1: Molecular structures of propargyl chloroformate (1) and phenyl chloroformate (2) and the 3D images for the syn conformer of propargyl chloroformate $\left(\mathbf{1}^{\prime}\right)$ and phenyl chloroformate $\left(\mathbf{2}^{\prime}\right)$.<smiles>COc1ccc(OC(=O)Cl)cc1</smiles><smiles>O=C(Cl)OCc1ccc([N+](=O)[O-])cc1</smiles>

5<smiles>O=C(Cl)Oc1ccc([N+](=O)[O-])cc1</smiles><smiles>O=C(Cl)OCc1ccccc1</smiles>

6<smiles>C=C(C)OC(=O)Cl</smiles>

7

FIGURE 2: Molecular structures of p-methoxyphenyl chloroformate (3), p-nitrophenyl chloroformate (4), p-nitrobenzyl chloroformate (5), benzyl chloroformate (6), and isopropenyl chloroformate (7).

$$
\searrow \mathrm{O}-\mathrm{C} \equiv \stackrel{\oplus}{\mathrm{O}} \longleftrightarrow \bigvee_{\oplus}^{\mathrm{O}}-\mathrm{C}=\mathrm{O} \longleftrightarrow \prod_{\oplus}^{\mathrm{O}}=\mathrm{C}=\mathrm{O}
$$

FIGURE 3: Resonance stabilized transition state of isopropenyl chloroformate (7).

and (2), to give (3). In (3), $h$ represents the sensitivity of solvolyses to changes in the aromatic ring parameter $I$

$$
\begin{gathered}
\log \left(\frac{k}{k_{o}}\right)=m Y_{\mathrm{X}}+h I+c, \\
\log \left(\frac{k}{k_{o}}\right)=l N_{\mathrm{T}}+m Y_{\mathrm{X}}+h I+c .
\end{gathered}
$$

In Scheme 1, we depict the solvolysis of phenyl chloroformate (PhOCOCl, 2) with the observed sensitivity values $[24,25]$ of $l=1.66$ and $m=0.56$ utilizing the extended Grunwald-Winstein equation (2). These values were obtained over the full range of the types of solvent usually incorporated into such studies, and these $l$ and $m$ values are now taken as typical values [19-21, 24, 25] for attack at an acyl $\left(\mathrm{sp}^{2}\right)$ carbon proceeding by the additionelimination mechanism, with the addition step being ratedetermining.

Figure 2 depicts the other aryl and alkenyl chloroformates that have been studied using (2). The aryl chloroformates $p$-methoxyphenyl (3) [25-28], p-nitrophenyl (4) $[25,27,29,30]$, and $p$-nitrobenzyl $(5)[31,32]$ were all shown to solvolyze like 2 by a dominant addition-elimination $\left(\mathrm{A}_{\mathrm{N}}+\right.$ 
TABLE 1: Specific rates of solvolysis $(k)$ of $\mathbf{1}$, in several binary solvents at $25.0^{\circ} \mathrm{C}$ and the literature values for $\left(N_{\mathrm{T}}\right)$ and $\left(Y_{\mathrm{Cl}}\right)$.

\begin{tabular}{|c|c|c|c|}
\hline Solvent $(\%)^{\mathrm{a}}$ & 1 at $25.0^{\circ} \mathrm{C} ; 10^{5} k, \mathrm{~s}^{-1 \mathrm{~b}}$ & $N_{\mathrm{T}}^{\mathrm{c}}$ & $Y_{\mathrm{Cl}}^{\mathrm{d}}$ \\
\hline $100 \% \mathrm{MeOH}$ & $63.4 \pm 1.2$ & 0.17 & -1.2 \\
\hline $90 \% \mathrm{MeOH}$ & $123 \pm 3$ & -0.01 & -0.20 \\
\hline $80 \% \mathrm{MeOH}$ & $178 \pm 10$ & -0.06 & 0.67 \\
\hline $100 \% \mathrm{EtOH}$ & $35.0 \pm 0.8$ & 0.37 & -2.50 \\
\hline $90 \% \mathrm{EtOH}$ & $53.9 \pm 1.2$ & 0.16 & -0.90 \\
\hline $80 \% \mathrm{EtOH}$ & $66.7 \pm 1.6$ & 0.00 & 0.00 \\
\hline $70 \% \mathrm{EtOH}$ & $86.7 \pm 1.7$ & -0.20 & 0.80 \\
\hline $95 \%$ Acetone & $1.09 \pm 0.03$ & -0.49 & -3.19 \\
\hline $90 \%$ Acetone & $2.46 \pm 0.10$ & -0.35 & -2.39 \\
\hline $80 \%$ Acetone & $7.52 \pm 0.22$ & -0.37 & -0.80 \\
\hline 97\% TFE (w/w) & $0.0190 \pm 0.0007$ & -3.30 & 2.83 \\
\hline $90 \%$ TFE $(w / w)$ & $0.342 \pm 0.007$ & -2.55 & 2.85 \\
\hline $80 \%$ TFE $(w / w)$ & $1.72 \pm 0.01$ & -2.22 & 2.90 \\
\hline $70 \% \operatorname{TFE}(\mathrm{w} / \mathrm{w})$ & $4.78 \pm 0.07$ & -1.98 & 2.96 \\
\hline $80 \mathrm{~T}-20 \mathrm{E}$ & $0.995 \pm 0.004$ & -1.76 & 1.89 \\
\hline $60 \mathrm{~T}-40 \mathrm{E}$ & $3.31 \pm 0.01$ & -0.94 & 0.63 \\
\hline $40 \mathrm{~T}-60 \mathrm{E}$ & $10.0 \pm 0.2$ & -0.34 & -0.48 \\
\hline $20 \mathrm{~T}-80 \mathrm{E}$ & $17.4 \pm 1.0$ & 0.08 & -1.42 \\
\hline 97\% HFIP (w/w) & $0.00116 \pm 0.00009$ & -5.26 & 5.17 \\
\hline $90 \%$ HFIP (w/w) & $0.0426 \pm 0.0020$ & -3.84 & 4.41 \\
\hline $80 \%$ HFIP (w/w) & $0.821 \pm 0.003$ & -3.31 & 3.99 \\
\hline $70 \%$ HFIP (w/w) & $13.9 \pm 0.8$ & -2.94 & 3.83 \\
\hline
\end{tabular}

${ }^{a}$ Substrate concentration of $c a$. $0.0052 \mathrm{M}$, binary solvents on a volumevolume basis at $25.0^{\circ} \mathrm{C}$, except for TFE- $\mathrm{H}_{2} \mathrm{O}$ and HFIP- $\mathrm{H}_{2} \mathrm{O}$ solvents which are on a weight-weight basis. T-E are TFE-ethanol mixtures. ${ }^{\mathrm{b}} \mathrm{With}$ associated standard deviation. ${ }^{\mathrm{c}}$ References $[16,17] .{ }^{\mathrm{d}}$ References [12-15].

$\left.D_{N}\right)$ mechanism with rate-determining formation of a tetrahedral transition state (Scheme 1). Benzyl chloroformate (6) followed the $A_{N}+D_{N}$ pathway in all binary aqueous organic mixtures except in the fluoroalcohols where a solvolysisdecomposition process was shown to be dominant [32].

The only alkenyl chloroformate studied using the extended Grunwald-Winstein analysis (2) is isopropenyl chloroformate (7) [33-35]. Zoon et al. analyzed the solvolyses of 7 [33] using (2) in 40 pure and binary organic mixtures at $10.0^{\circ} \mathrm{C}$. Together with kinetic solvent isotope effect (KSIE) data of 2.33, they concluded [33] that the solvolytic reactions for 7 fit a third-order reaction mechanism involving attack by a solvent nucleophile assisted by another molecule of solvent acting as a general base, and the rate data could be dissected into contributions from four competing reaction channels in the alcohol-water solvent systems [33]. Koh and Kang [34] studied the solvolysis of 7 at $35.0^{\circ} \mathrm{C}$ in 33 solvents including the highly ionizing aqueous $1,1,1,3,3,3$ hexafluoro-2-propanol (HFIP) and 2,2,2-trifluoroethanol (TFE) mixtures. On application of (2), they obtained an $l$ value of 1.42 and an $m$ value of 0.46 [34] and suggested that 7 solvolyzed by an addition-elimination $\left(A_{N}+D_{N}\right)$ mechanism involving rate-limiting attack by the solvent at the carbonyl carbon of 7 . With the $k_{\mathrm{MeOH}} / k_{\mathrm{MeOD}}$ data of 2.19 achieved [34], they inferred that a general base catalysis is also superimposed upon the $\mathrm{A}_{\mathrm{N}}+\mathrm{D}_{\mathrm{N}}$ bimolecular process.

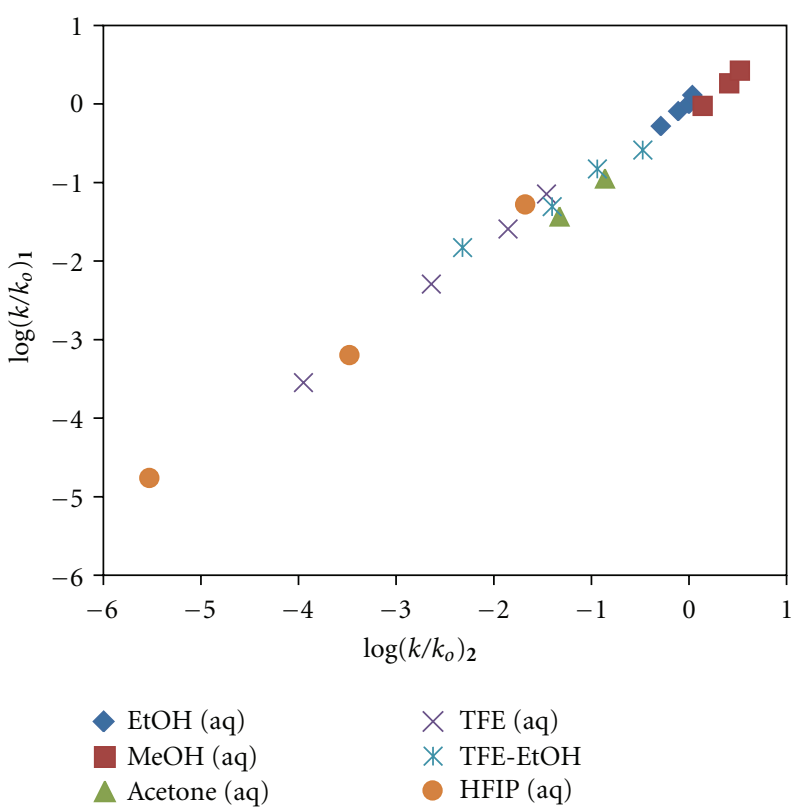

FIGURE 4: The plot of $\log \left(k / k_{o}\right)$ for propargyl chloroformate (1) against $\log \left(k / k_{o}\right)$ for phenyl chloroformate $(2)$ in common pure and binary solvents at $25.0^{\circ} \mathrm{C}$.

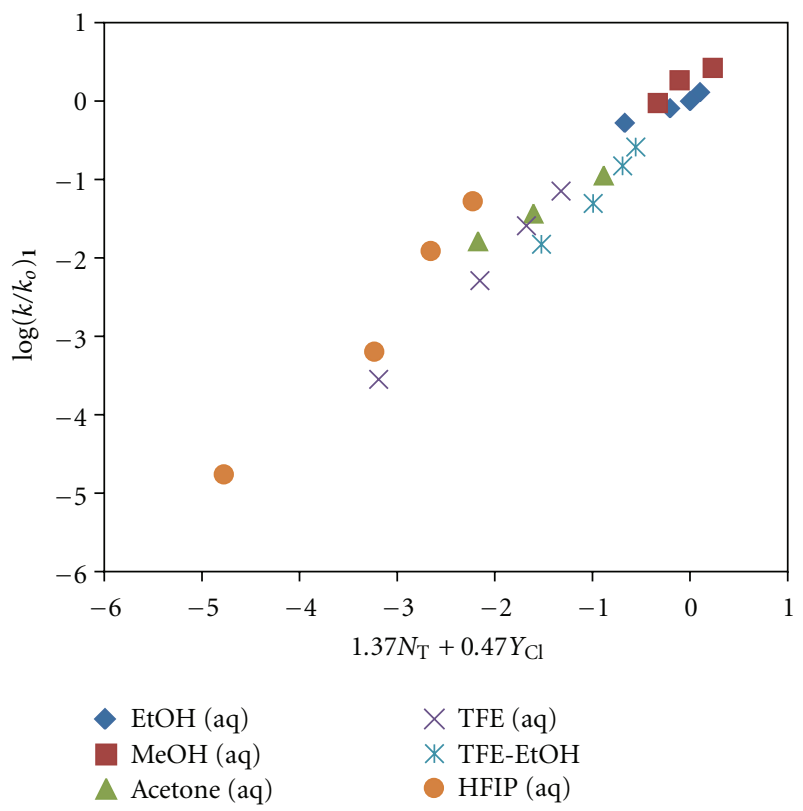

FIGURE 5: The plot of $\log \left(k / k_{o}\right)$ for propargyl chloroformate (1) against $1.37 N_{\mathrm{T}}+0.47 Y_{\mathrm{Cl}}$.

Recently, we completed an exhaustive evaluation [35] of the solvolysis of 7 at $10.0^{\circ} \mathrm{C}$ in 51 solvents with widely varying nucleophilicity and ionizing power values. Outcomes acquired through the application of the extended GrunwaldWinstein equation (2) resulted [35] in the proposal of an addition-elimination $\left(A_{N}+D_{N}\right)$ mechanism dominating in most of the solvents, but in 97-70\% HFIP, and 97\% TFE, a superimposed $\mathrm{S}_{\mathrm{N}} 1$-type ionization is making a significant 
TABLE 2: Correlation of the specific rates of reaction of 1-7 using the extended Grunwald-Winstein equation (2).

\begin{tabular}{|c|c|c|c|c|c|c|c|}
\hline Substrate & $n^{\mathrm{a}}$ & $l^{\mathrm{b}}$ & $m^{\mathrm{b}}$ & $l / m$ & $c^{\mathrm{c}}$ & $R^{\mathrm{d}}$ & $F^{\mathrm{e}}$ \\
\hline \multirow[t]{2}{*}{1} & 22 & $1.37 \pm 0.10$ & $0.47 \pm 0.07$ & 2.91 & $0.11 \pm 0.11$ & 0.970 & 152 \\
\hline & $20^{\mathrm{f}}$ & $1.44 \pm 0.11$ & $0.51 \pm 0.08$ & 2.82 & $0.12 \pm 0.10$ & 0.977 & 181 \\
\hline \multirow[t]{2}{*}{2} & $49^{g}$ & $1.66 \pm 0.05$ & $0.56 \pm 0.03$ & 2.96 & $0.15 \pm 0.07$ & 0.980 & 568 \\
\hline & $20^{\mathrm{h}}$ & $1.55 \pm 0.13$ & $0.48 \pm 0.09$ & 3.23 & $0.14 \pm 0.12$ & 0.978 & 186 \\
\hline 3 & $44^{\mathrm{i}}$ & $1.60 \pm 0.05$ & $0.57 \pm 0.05$ & 2.81 & $0.18 \pm 0.06$ & 0.981 & 517 \\
\hline 4 & $39^{j}$ & $1.68 \pm 0.06$ & $0.46 \pm 0.04$ & 3.65 & $0.074 \pm 0.08$ & 0.976 & 363 \\
\hline 5 & $19^{\mathrm{k}}$ & $1.61 \pm 0.09$ & $0.46 \pm 0.04$ & 3.50 & $0.04 \pm 0.22$ & 0.975 & 157 \\
\hline \multirow[t]{2}{*}{6} & $15^{1}$ & $1.95 \pm 0.16$ & $0.57 \pm 0.05$ & 3.42 & $0.16 \pm 0.15$ & 0.966 & 83 \\
\hline & $11^{1}$ & $0.25 \pm 0.05$ & $0.66 \pm 0.06$ & 0.38 & $-2.05 \pm 0.11$ & 0.976 & 80 \\
\hline 7 & $50^{\mathrm{m}}$ & $1.54 \pm 0.06$ & $0.54 \pm 0.03$ & 2.85 & $0.05 \pm 0.06$ & 0.968 & 347 \\
\hline
\end{tabular}

${ }^{\mathrm{a}} n$ is the number of solvents. ${ }^{\mathrm{b}}$ With associated standard error. ${ }^{\mathrm{c}}$ Accompanied by standard error of the estimate. ${ }^{\mathrm{d}}$ Correlation coefficient. ${ }^{\mathrm{e}} F$-test value. ${ }^{\mathrm{f}} \mathrm{No}$ 95A, 80HFIP, to compare with 2 in identical solvents. ${ }^{g}$ Values taken from $[24,25] .{ }^{\mathrm{h}}$ To compare with 1 in identical solvents. ${ }^{\mathrm{i}}$ Values taken from [25, 28]. ${ }^{j}$ Values taken from [30]. ${ }^{\mathrm{k}}$ Values taken from $[31,32] .{ }^{1}$ Values taken from [32]. ${ }^{\mathrm{m}}$ Values taken from [35].

contribution. We proposed [35] that for the solvolysis of 7 in $97 \%$ HFIP, $97 \%$ of the reaction undergoes solvolyses by an ionization $\left(\mathrm{S}_{\mathrm{N}} 1\right)$ process and in $90 \%$ HFIP, $70 \%$ HFIP, and $97 \%$ TFE, the corresponding \% ionization values are $70 \%$, $64 \%$, and $35 \%$, respectively. We suggested [35] that such superimposed unimolecular $\left(\mathrm{S}_{\mathrm{N}} 1\right)$ processes are observed in the highly ionizing aqueous fluoroalcohol mixtures for $\mathbf{7}$ are due to the formation of a resonance stabilized transition state shown in Figure 3.

In this paper, we will now report our analyses for the first alkynyl ester, propargyl chloroformate (1), to be studied using the extended Grunwald-Winstein equation (2) in a variety of mixed aqueous organic solvents at $25.0^{\circ} \mathrm{C}$. Theoretically, this ester (1) like benzyl chloroformate (6) [32] could undergo heterolytic bond cleavage in a solvolysisdecomposition type process with loss of $\mathrm{CO}_{2}$ with the formation of a resonance stabilized intermediate.

\section{Results and Discussion}

The first-order specific rates of solvolysis for 1 were determined in 22 solvents at $25.0^{\circ} \mathrm{C}$. The solvents consisted of methanol $(\mathrm{MeOH})$, ethanol $(\mathrm{EtOH})$, and binary mixtures of water with methanol, ethanol, acetone, TFE, or HFIP, plus binary mixtures of TFE with ethanol. These values together with the literature values for $N_{\mathrm{T}}[16,17]$ and $Y_{\mathrm{Cl}}[12-15]$ are reported in Table 1.

A comparison of the specific rates of solvolysis for 1 (Table 1) with those previously reported for $2[24,25,27]$ at $25.0^{\circ} \mathrm{C}$ gives $k_{2} / k_{1}$ ratios of 6 to 11 in the aqueous ethanol, methanol, and acetone mixtures, ratios of 2 to 4 in the more aqueous fluoroalcohols, and a ratio of 1.3 in the highly ionizing 97\% HFIP. This rate sequence implies that a similar biomolecular mechanism is occurring in both substrates with the inductive effect of the phenoxy group being much greater than that of the propargoxy group. Such differences in electron withdrawing character are further corroborated by the 3D images for propargyl chloroformate $\left(\mathbf{1}^{\prime}\right)$ and phenyl chloroformate $\left(\mathbf{2}^{\prime}\right)$ shown in Figure 1, where due to the presence of the additional methyl group, the alkynyl group is twisted out of the plane of the ether oxygen.

A plot of $\log \left(k / k_{0}\right)$ for propargyl chloroformate (1) against $\log \left(k / k_{o}\right)$ for phenyl chloroformate (2) is shown in Figure 4. This graph has an $R$ value of 0.996 , an $F$-test of 2161 , a slope of $0.86 \pm 0.02$, and an intercept of $-0.04 \pm$ 0.04 . These values provide strong evidence that 1 undergoes solvolysis by a similar mechanism to 2 .

In Table 2, we report the results obtained on application of the extended Grunwald-Winstein equation (2) to the specific rates of solvolysis of $\mathbf{1}$ in all of the 22 solvents studied. We obtain an $l$ value of $1.37 \pm 0.10$, an $m$ value of $0.47 \pm 0.07$, an $l / m$ ratio of 2.91 , a correlation coefficient $(R)$ of 0.970 , an $F$-test value of 152 , and an intercept of $0.11 \pm 0.11$. The $\mathrm{l} / \mathrm{m}$ ratio of $\mathbf{1}$ in 22 solvents is similar to that reported for $\mathbf{2}$ $[24,25]$ in 49 solvents (Table 2).

In Table 2, we also report the analyses obtained for $\mathbf{1}$ using (2) in 20 solvents (no 95\% acetone, 80\% HFIP). We report $1.44 \pm 0.11$ for $l, 0.51 \pm 0.08$ for $m$, an $l / m$ ratio of 2.82 , $R=0.977$, an $F$-test value of 181 , and $c=0.12 \pm 0.10$. For 2 in the identical 20 solvents, we get $1.55 \pm 0.13$ for $l, 0.48 \pm 0.09$ for $m$, an $l / m$ ratio of $3.23, R=0.978, F$-test $=186$, and an intercept of $0.14 \pm 0.12$. These statistical values coupled with the data reported above for Figure 4, strongly demonstrates that $\mathbf{1}$ and $\mathbf{2}$ undergo a very similar bimolecular additionelimination $\left(A_{N}+D_{N}\right)$ process with the addition-step being rate determining.

The solvolyses of 7 at $25.0^{\circ} \mathrm{C}$ were studied [35] in $100 \% \mathrm{EtOH}\left(110 \pm 6 \times 10^{-5} \mathrm{~s}^{-1}\right), 100 \% \mathrm{MeOH}(210 \pm 8 \times$ $\left.10^{-5} \mathrm{~s}^{-1}\right), 70 \% \operatorname{HFIP}\left(2.54 \pm 0.09 \times 10^{-5} \mathrm{~s}^{-1}\right)$, and 50\% HFIP $\left(35.2 \pm 3.1 \times 10^{-5} \mathrm{~s}^{-1}\right)$. The corresponding $k_{7} / k_{1}$ ratios in the common solvents studied are 3.14 in pure EtOH, 3.31 in $100 \% \mathrm{MeOH}$, and 0.18 in $70 \%$ HFIP. These results showing only small differences between $k_{7}$ and $k_{1}$ in $\mathrm{MeOH}$ and EtOH affirm the proposal [35] that 7 undergoes solvolysis by a stepwise addition-elimination $\left(A_{N}+D_{N}\right)$ with a ratedetermining addition step. The rates of solvolysis of 7 are 3 -fold faster in $\mathrm{MeOH}$ and $\mathrm{EtOH}$ when compared to those 
of $\mathbf{1}$ due to the proximity of the alkenyl group and the ether oxygen in 7 and the fact that the alkynyl group is pushed out of the plane of the ether oxygen in $\mathbf{1}$.

A plot of $\log \left(k / k_{o}\right)$ for propargyl chloroformate (1) against $1.37 N_{\mathrm{T}}+0.47 Y_{\mathrm{Cl}}$ shown in Figure 5 shows that the 97\% HFIP and 90\% HFIP points lie slightly above the regression line. Removing of these two data points and on using (2) in the remaining 20 solvents, we get an $l$ value of $1.33 \pm 0.13, m=0.46 \pm 0.07, R=0.944, F$-test $=69$, and $c=0.09 \pm 0.12$. The much lower $R$ and $F$-test values obtained using these 20 solvents when compared to those obtained with (2) using all of the 22 solvents studied (Table 2) suggest that the plot shown in Figure 5 is robust and that the addition-elimination $\left(A_{N}+D_{N}\right)$ process dominates in all of the 22 solvents studied.

\section{Conclusions}

The mechanism of reaction for the solvolysis of propargyl chloroformate (1) in all 22 solvents with widely ranging nucleophilicity and ionizing power values is found to closely mimic that of the previously studied phenyl chloroformate (2). For 1 in all 22 solvents, we propose an additionelimination $\left(A_{N}+D_{N}\right)$ process with the addition-step being rate determining.

The $k_{2} / k_{1}$ rate ratios suggest that the inductive ability of the alkynoxy group in $\mathbf{1}$ is reduced because the alkynyl group is pushed out the plane of the ether oxygen. The extended Grunwald-Winstein equation (2) is again shown to be very sensitive in deciphering solvents effects.

\section{Experimental Section}

The propargyl chloroformate (Sigma-Aldrich, 97\%) was used as received. Solvents were purified and the kinetic runs carried out as described previously [24]. A substrate concentration of approximately $0.005 \mathrm{M}$ in a variety of solvents was employed. The specific rates and associated standard deviations, as presented in Table 1, are obtained by averaging all of the values from, at least, duplicate runs.

Multiple regression analyses were carried out using the Excel 2007 package from the Microsoft Corporation. The $3 \mathrm{D}$-views presented in Figure 1 were computed using the KnowItAll Informatics System, ADME/Tox Edition, from BioRad Laboratories, Philadelphia, Pa, USA.

\section{Acknowledgments}

This research was supported by Grant no. 2 P2O RR01647210 from the National Center for Research Resources (NCRR), a component of the National Institutes of Health (NIH). This IDeA Network of Biomedical Research Excellence (INBRE) Grant to the state of Delaware was obtained under the leadership of the University of Delaware, and the authors sincerely appreciate their efforts. A. M. Darrington received an INBRE-supported Undergraduate Research Assistantship in the Directed Research Program in Chemistry at Wesley College. Additionally, A. M. Darrington received an Undergraduate Tuition Scholarship through the NASA funded Delaware Space Grant Consortium program (no. NNG05GO92H) at the University of Delaware. In March 2010, at the 239th National American Chemical Society (ACS) Meeting, San Francisco, CA, this project was presented as a poster in the Undergraduate Section of the Division of Chemical Education (CHED) and received a Certificate of Merit.

\section{References}

[1] J. Tejler, E. Tullberg, T. Frejd, H. Leffler, and U. J. Nilsson, "Synthesis of multivalent lactose derivatives by 1,3-dipolar cycloadditions: selective galectin-1 inhibition," Carbohydrate Research, vol. 341, no. 10, pp. 1353-1362, 2006.

[2] R. G. Bhat, Y. Ghosh, and S. Chandrasekaran, "A mild and selective method for $N$-dealkylation of tertiary amines," Tetrahedron Letters, vol. 45, no. 43, pp. 7983-7985, 2004.

[3] C. Lu and W. Zhong, "Synthesis of propargyl-terminated heterobifunctional poly(ethylene glycol)," Polymers, vol. 2, pp. 407-417, 2010.

[4] M. Yamada, "Polymerizable carbonates having ethylenic and acetylenic functions," United States Patent 5194655, 1993.

[5] D. N. Kevill, "Chloroformate esters and related compounds," in The Chemistry of the Functional Groups: The Chemistry of Acyl Halides, S. Patai, Ed., chapter 12, pp. 381-453, John Wiley \& Sons, New York, NY, USA, 1972.

[6] S. Mario, The War Gases, Chemistry and Analysis, Van Nostrand Company, Inc., New York, NY, USA, 1939, Translated by L. W. Morrison.

[7] N. S. True and R. K. Bohn, "Low resolution microwave spectroscopy. 5. Rotational isomerism of propargyl cyanoformate, propargyl trifluoroacetate, propargyl fluoroformate, and propargyl chloroformate," Journal of the American Chemical Society, vol. 99, no. 11, pp. 3575-3579, 1977.

[8] T. W. Bentley, "Structural effects on the solvolytic reactivity of carboxylic and sulfonic acid chlorides. Comparisons with gas-phase data for cation formation," Journal of Organic Chemistry, vol. 73, no. 16, pp. 6251-6257, 2008.

[9] E. Grunwald and S. Winstein, "The correlation of solvolysis rates," Journal of the American Chemical Society, vol. 70, no. 2, pp. 846-854, 1948.

[10] S. Winstein, E. Grunwald, and H. W. Jones, "The correlation of solvolysis rates and the classification of solvolysis reactions into mechanistic categories," Journal of the American Chemical Society, vol. 73, no. 6, pp. 2700-2707, 1951.

[11] P. V. R. Schleyer and R. D. Nicholas, "The reactivity of bridgehead compounds of adamantane," Journal of the American Chemical Society, vol. 83, no. 12, pp. 2700-2707, 1961.

[12] T. W. Bentley and P. V. R. Schleyer, "Medium effects on the rates and mechanisms of solvolytic reactions," Advances in Physical Organic Chemistry, vol. 14, pp. 1-67, 1977.

[13] T. W. Bentley and G. Llewellyn, " $Y_{X}$ scales of solvent ionizing power," Progress in Physical Organic Chemistry, vol. 17, pp. 121-158, 1990.

[14] D. N. Kevill and M. J. D'Souza, "Additional $Y_{\mathrm{Cl}}$ values and correlation of the specific rates of solvolysis of tert-butyl chloride in terms of $N_{\mathrm{T}}$ and $Y_{\mathrm{Cl}}$ scales," Journal of Chemical Research, vol. 5, pp. 174-175, 1993. 
[15] D. N. Kevill and H. R. Zoon, "Additional solvent ionizing power values for binary water-1,1,1,3,3,3- hexafluoro-2propanol solvents," International Journal of Molecular Sciences, vol. 7, no. 10, pp. 451-455, 2006.

[16] D. N. Kevill and S. W. Anderson, "An improved scale of solvent nucleophilicity based on the solvolysis of the Smethyldibenzothiophenium ion," Journal of Organic Chemistry, vol. 56, no. 5, pp. 1845-1850, 1991.

[17] D. N. Kevill, "Development and uses of scales of solvent nucleophilicity," in Advances in Quantitative Structure-Property Relationships, M. Charton, Ed., vol. 1, pp. 81-115, JAI Press, Greenwich, Conn, USA, 1996.

[18] T. W. Bentley and M. S. Garley, "Correlations and predictions of solvent effects on reactivity: some limitations of multiparameter equations and comparisons with similarity models based on one solvent parameter," Journal of Physical Organic Chemistry, vol. 19, no. 6, pp. 341-349, 2006.

[19] T. W. Bentley, H. C. Harris, Z. H. Ryu, G. T. Lim, D. D. Sung, and S. R. Szajda, "Mechanisms of solvolyses of acid chlorides and chloroformates. Chloroacetyl and phenylacetyl chloride as similarity models," Journal of Organic Chemistry, vol. 70, no. 22, pp. 8963-8970, 2005.

[20] D. N. Kevill and M. J. D'Souza, "Sixty years of the GrunwaldWinstein equation: development and recent applications," Journal of Chemical Research, no. 2, pp. 61-66, 2008.

[21] M. J. D’Souza, Z. H. Ryu, B. C. Park, and D. N. Kevill, "Correlation of the rates of solvolysis of acetyl chloride and $\alpha$-substituted derivatives," Canadian Journal of Chemistry, vol. 86, no. 5, pp. 359-367, 2008.

[22] D. N. Kevill and M. J. D'Souza, "Use of the simple and extended grunwald-winstein equations in the correlation of the rates of solvolysis of highly hindered tertiary alkyl derivatives," Current Organic Chemistry, vol. 14, no. 10, pp. 1037-1049, 2010.

[23] D. N. Kevill, N. H. J. Ismail, and M. J. D’Souza, “Solvolysis of the ( $p$-methoxybenzyl)dimethylsulfonium ion. Development and use of a scale to correct for dispersion in GrunwaldWinstein plots," Journal of Organic Chemistry, vol. 59, no. 21, pp. 6303-6312, 1994.

[24] D. N. Kevill and M. J. D'Souza, "Correlation of the rates of solvolysis of phenyl chloroformate," Journal of the Chemical Society. Perkin Transactions 2, no. 9, pp. 1721-1724, 1997.

[25] D. N. Kevill, F. Koyoshi, and M. J. D’Souza, “Correlations of the specific rates of solvolysis of aromatic carbamoyl chlorides, chloroformates, chlorothionoformates, and chlorodithioformates revisited," International Journal of Molecular Sciences, vol. 8, no. 4, pp. 346-362, 2007.

[26] I. S. Koo, K. Yang, JA. C. Koo, J. K. Park, and I. Lee, "Stoichiometric solvation effects. Part 4. Product-rate correlations for solvolyses of $p$-methoxyphenyl chloroformate in alcoholwater mixtures," Bulletin of the Korean Chemical Society, vol. 18, no. 9, pp. 1017-1021, 1997.

[27] I. S. Koo, K. Yang, K. Kang, and I. Lee, "Transition-state variation in the solvolyses of para-substiuted phenyl chloroformates in alcohol-water mixtures," Bulletin of the Korean Chemical Society, vol. 19, no. 9, pp. 968-973, 1998.

[28] M. J. D’Souza, D. Reed, F. Koyoshi, and D. N. Kevill, "Consideration of the factors influencing the specific rates of solvolysis of $p$-methoxyphenyl chloroformate," International Journal of Molecular Sciences, vol. 8, no. 8, pp. 788-796, 2007.

[29] I. S. Koo, K. Yang, K. Kang, I. Lee, and T. W. Bentley, "Stoichiometric solvation effects. Part 3. Product-rate correlations for solvolyses of $p$-nitrophenyl chloroformate in alcohol-water mixtures," Journal of the Chemical Society. Perkin Transactions 2, no. 5, pp. 1179-1183, 1998.

[30] M. J. D’Souza, K. E. Shuman, S. E. Carter, and D. N. Kevill, "Extended Grunwald-Winstein analysis - LFER used to gauge solvent effects in p-nitrophenyl chloroformate solvolysis," International Journal of Molecular Sciences, vol. 9, no. 11, pp. 2231-2242, 2008.

[31] K. H. Park, J. B. Kyong, and D. N. Kevill, "Nucleophilic substitution reactions of $p$-nitrobenzyl chloroformate," Bulletin of the Korean Chemical Society, vol. 21, no. 12, pp. 1267-1270, 2000.

[32] J. B. Kyong, B. C. Park, C. B. Kim, and D. N. Kevill, "Rate and product studies with benzyl and $p$-nitrobenzyl chloroformates under solvolytic conditions," Journal of Organic Chemistry, vol. 65, no. 23, pp. 8051-8058, 2000.

[33] H. R. Zoon, H. L. Young, and Y. Oh, "Stoichiometric effects. Correlation of the rates of solvolysis of isopropenyl chloroformate," Bulletin of the Korean Chemical Society, vol. 26, no. 11, pp. 1761-1766, 2005.

[34] H. J. Koh and S. J. Kang, "Kinetic studies of the solvolyses of isopropenyl chloroformate," Bulletin of the Korean Chemical Society, vol. 31, no. 6, pp. 1793-1796, 2010.

[35] M. J. D’Souza, K. E. Shuman, A. O. Omondi, and D. N. Kevill, "Detailed analysis for the solvolysis of isopropenyl chloroformate," European Journal of Chemistry. In press. 


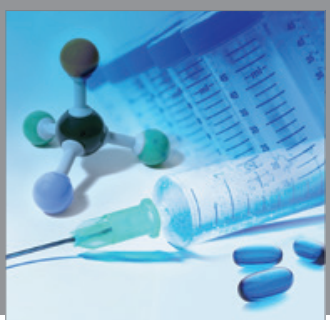

International Journal of

Medicinal Chemistry

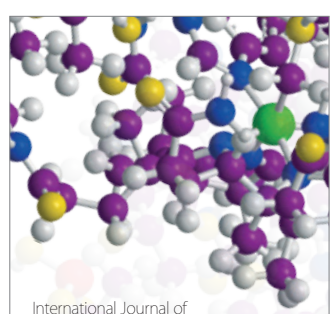

Carbohydrate Chemistry

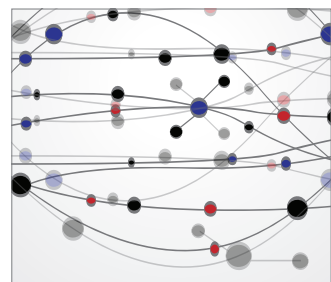

The Scientific World Journal
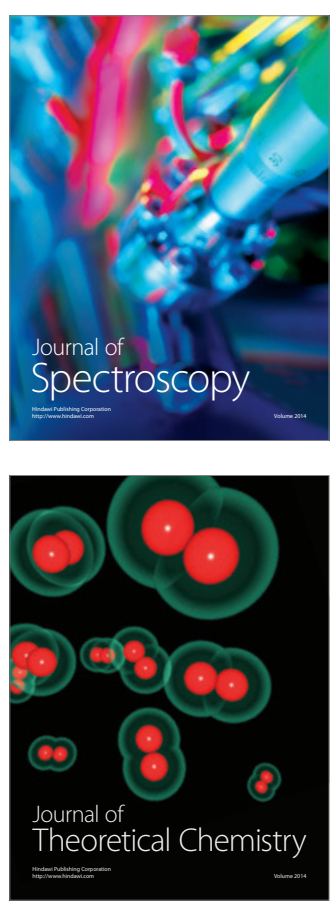
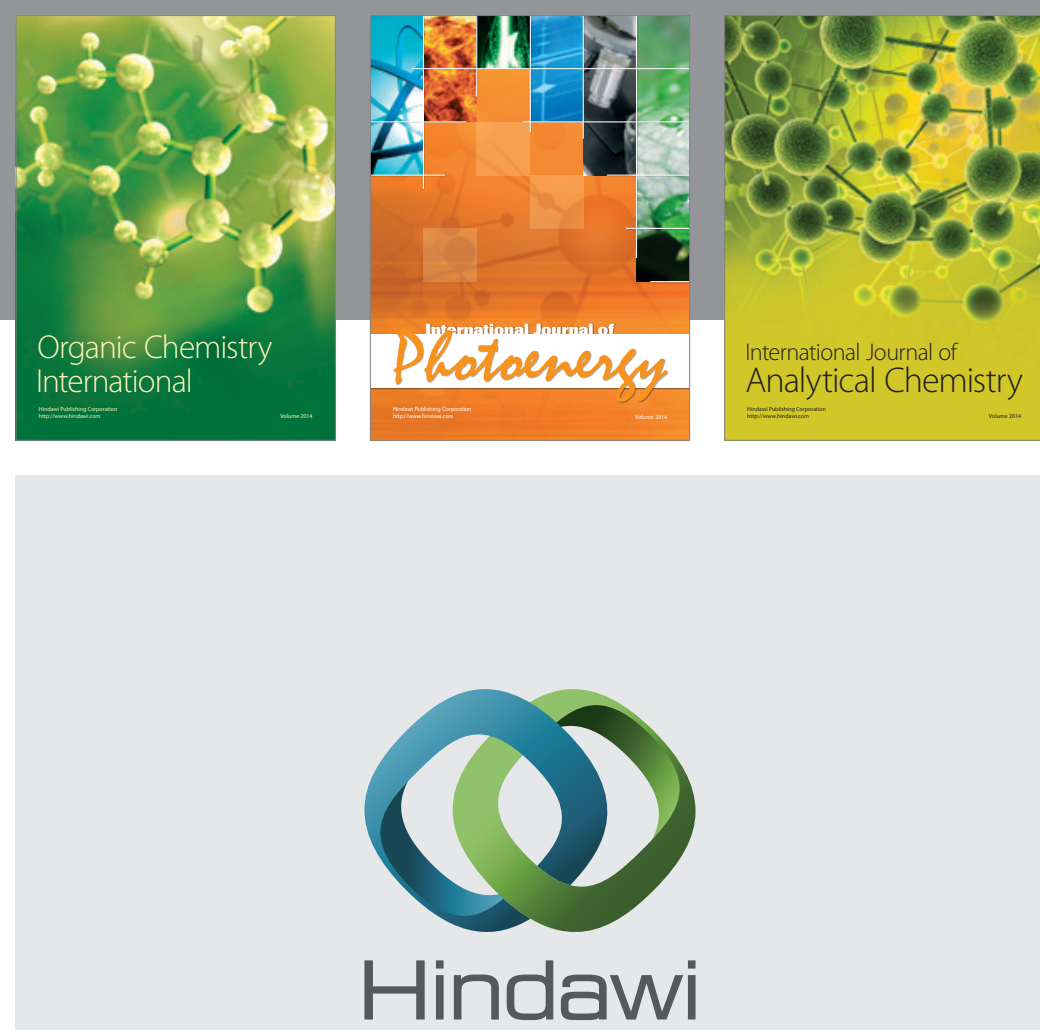

Submit your manuscripts at

http://www.hindawi.com
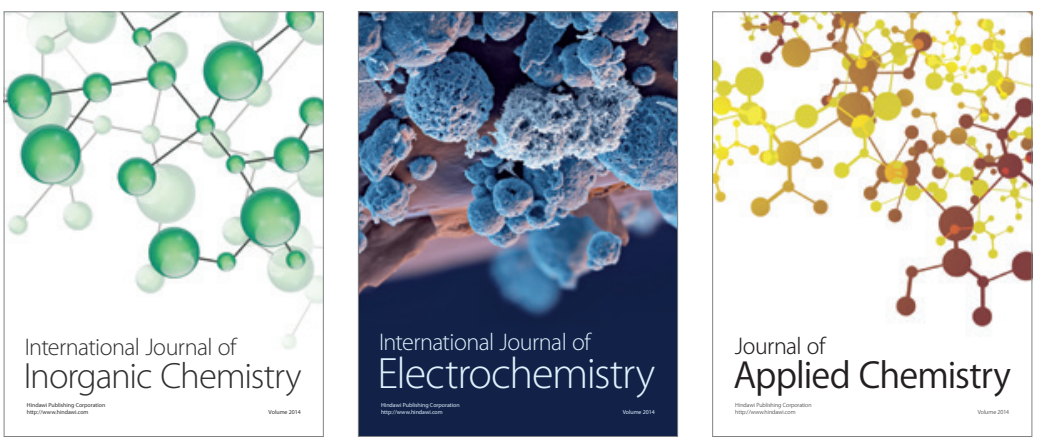

Journal of

Applied Chemistry
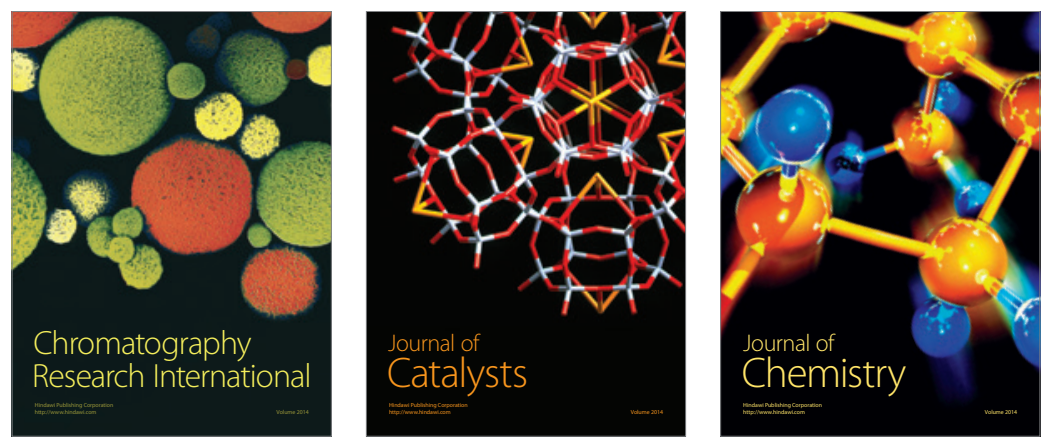
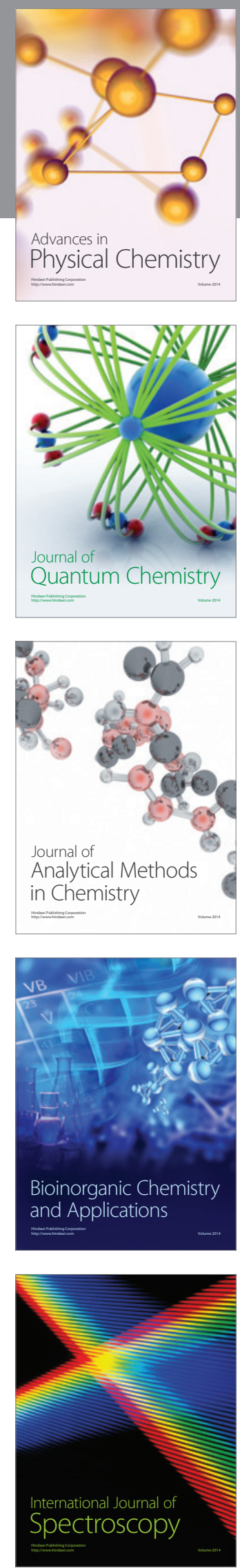